\title{
Severe Convective Storm Environments in Turkey
}

\author{
ABDUllah KaHRAMAN \\ Graduate School of Science, Engineering and Technology, Istanbul Technical University, Istanbul, Turkey \\ Mikdat KAdioglu \\ Department of Meteorological Engineering, Istanbul Technical University, Istanbul, Turkey \\ PAUL M. MARKOWSKI \\ Department of Meteorology and Atmospheric Sciences, The Pennsylvania State University, \\ University Park, Pennsylvania
}

(Manuscript received 31 August 2016, in final form 30 September 2017)

\begin{abstract}
Severe convective storms occasionally result in loss of life and property in Turkey, a country not known for its severe convective weather. However, relatively little is known about the characteristics of Turkish severe weather environments. This paper documents these characteristics using European Centre for MediumRange Weather Forecasts (ECMWF) reanalysis data on tornado and severe hail days in Turkey from 1979 to 2013. Severe storm environments are characterized by larger convective available potential energy (CAPE) in Turkey compared to the rest of Europe, but the CAPE values are less than those in typical U.S. severe storm environments. Severe hail is associated with large CAPE and vertical wind shear. Nonmesocyclonic tornadoes are associated with less CAPE compared with the other forms of severe weather. Deep-layer vertical wind shear is slightly weaker in Turkish supercell environments than in U.S. supercell environments, and Turkish tornadic supercell environments are characterized by much weaker low-level shear than in the United States and Europe, at least in the ECMWF reanalysis data. Composite parameters such as the supercell composite parameter (SCP) and energy-helicity index (EHI) can discriminate between very large hail and large hail environments.
\end{abstract}

\section{Introduction}

Skillful forecasting of convective storms and their attendant hazards, such as tornadoes or large hail, requires knowledge of the characteristics of the environments in which the phenomena tend to occur. Existing studies of environmental conditions supportive of severe convective storms cover mainly the United States and parts of Europe. Rasmussen and Blanchard (1998) analyzed National Weather Service soundings from 1992 and focused on discriminating between environments associated with supercells that produced tornadoes of F2 intensity and stronger (deemed "significant" tornadoes), supercells without significant tornadoes, and nonsupercell thunderstorms. A subsequent study by

Corresponding author: Abdullah Kahraman, kahraman@ meteogreen.com
Thompson et al. (2003) utilized soundings from 40-km Rapid Update Cycle 2 (RUC-2) analyses to investigate environments of "significantly tornadic" supercells, "weakly tornadic" supercells, nontornadic supercells, and discrete nonsupercell storms between April 1999 and June 2001. Furthermore, Johnson and Sugden (2014) used RUC analyses to study U.S. large hail environments, though the RUC analyses had a higher resolution than in the Thompson et al. (2003) study (20and 13-km grid intervals between 2003 and 2011). Investigations in more localized regions also have been performed for parts of North America using gridded model analyses and observed soundings. For example, Lombardo and Colle (2011) investigated the relationship between the structure of the convection ("cellular," "linear," and "nonlinear" cases were identified) and the characteristics of the environment in severe convective weather events in the northeastern United States for the 
warm seasons between 2002 and 2007, using North American Regional Reanalysis data (32-km grid spacing). Dupilka and Reuter (2011) examined the environments of $\mathrm{F} 2+$ tornadoes, $\mathrm{F} 0-\mathrm{F} 1$ tornadoes, and nontornadic storms with $\geq 3$-cm hail within central Alberta, Canada, between 1967 and 2000, using observed soundings.

Studies of convective storm environments covering the entire continent of Europe are generally lacking, in large part because of the inhomogeneity of storm data reports across Europe from one country to another. Thus, investigations that rely on storm reports tend to be limited to small regions or individual countries. In a study covering most of Europe, Kaltenböck et al. (2009) used soundings obtained from European Centre for Medium-Range Weather Forecasts (ECMWF) gridded analyses for April-September 2006-07, to investigate the environments of F2-F3 tornadoes, F0-F1 tornadoes, severe hail events, severe wind events, heavy precipitation events, thunderstorms, and null cases. As an example for studies covering smaller regions, Groenemeijer and Van Delden (2007) used observed soundings obtained within and in close proximity to the Netherlands between 1975 and 2003 to investigate the environments of F1+ tornadoes, F0 tornadoes, waterspouts, hail $\geq 3 \mathrm{~cm}$, hail $<3 \mathrm{~cm}$, thunder, and no severe weather in the country. Further studies have been performed for Poland, Finland, coastal Croatia, and parts of Spain for some severe weather types. Taszarek and Kolendowicz (2013) studied a total of 97 tornado cases with radiosonde observations in and around Poland between 1977 and 2012. Tuovinen et al. (2015) studied 23 significant hail day soundings and 93 null thunderstorm soundings in Finland between 1972 and 2011. Renko et al. (2016) studied the environments of 62 waterspouts in the eastern Adriatic Sea (Croatian coasts) using radiosonde observations between 2001 and 2013. Merino et al. (2013) compared 100 days between 2001 and 2010 with and without hail in northeastern Spain, using soundings obtained from WRF simulations with 9-km horizontal grid spacing. Finally, for a broader area in central Europe, Púčik et al. (2015) investigated the characteristics of 16421 radiosondes associated with thunderstorms (of which 3866 were associated with at least one severe weather occurrence) between 2007 and 2013.

Additional studies have compared the characteristics of convective storm environments in North America and Europe. Brooks (2009) studied 159 significant tornado soundings and 1031 significant nontornadic soundings in the United States between 1997 and 1999, and 152 "significant tornadic" soundings and 61 "significant nontornadic" soundings in Europe between 1958 and 1999 using National Centers for Environmental Prediction-National Center for Atmospheric Research (NCEP-NCAR) reanalysis data.
Grünwald and Brooks (2011) subsequently used the same reanalysis dataset to compare the environments associated with 303 tornadoes in Europe between 1958 and 1999, and 4510 tornadoes in the United States between 1991 and 1999.

Deep moist convection tends to become increasingly organized as the vertical wind shear increases (Markowski and Richardson 2010). The magnitude of the vector wind difference between the near-surface wind (typically $10 \mathrm{~m}$ AGL) and the $6 \mathrm{~km}$ AGL wind, hereafter the 0-6-km shear, has been a popular bulk measure of the vertical wind shear within the forecasting community (e.g., Bunkers 2002; Houston et al. 2008). Disorganized convection (sometimes called single-cell convection) is typical of environments having $0-6-\mathrm{km}$ shear less than $10 \mathrm{~m} \mathrm{~s}^{-1}$. For $0-6-\mathrm{km}$ shear of roughly $10-20 \mathrm{~m} \mathrm{~s}^{-1}$, multicellular convection can occur (e.g., squall lines and other convective systems). For $0-6-\mathrm{km}$ shear exceeding roughly $15 \mathrm{~m} \mathrm{~s}^{-1}$, supercells are possible, at least in the case of relatively isolated convective storms (severe squall lines also can occur in the presence of strong shear). The strong vertical shear in supercell environments is the source of horizontal vorticity, which, upon tilting into the vertical, gives rise to the midtropospheric mesocyclones of supercell storms.

Low-level shear is crucial for mesocyclonic tornadoes, and $10 \mathrm{~m} \mathrm{~s}^{-1}$ bulk shear for the $0-1-\mathrm{km}$ layer is a rough lower bound for favorable environments for significant tornadoes. Thompson et al. (2003) found that weak tornadoes in the United States occur with $0-1-\mathrm{km}$ shear of $8.1 \mathrm{~m} \mathrm{~s}^{-1}$ (median value), with an interquartile range of $5.7-11.3 \mathrm{~m} \mathrm{~s}^{-1}$; for significant tornadoes the median $0-1-\mathrm{km}$ shear is $9.8 \mathrm{~m} \mathrm{~s}^{-1}$, with an interquartile range of $7.8-13.6 \mathrm{~m} \mathrm{~s}^{-1}$. In the Netherlands, this parameter is a good discriminator for significant tornadoes (a $20.3 \mathrm{~m} \mathrm{~s}^{-1}$ median value, with a $13.2-22.1 \mathrm{~m} \mathrm{~s}^{-1}$ interquartile range for $\mathrm{F} 2$ tornadoes versus $9.0 \mathrm{~m} \mathrm{~s}^{-1}$ median value, with a 7.3-12.1 $\mathrm{m} \mathrm{s}^{-1}$ interquartile range for $\mathrm{F} 1$ tornadoes), and also the intensity of tornadoes (Groenemeijer and Van Delden 2007). However, for Poland, low-level shear values in the environments of tornadic storms are less than those in Dutch tornadic storm environments (Taszarek and Kolendowicz 2013). Lesser low-level shear is also the case for central Europe as a whole, as shown by Púčik et al. (2015). The 25th-75th percentiles of 0-1-km shear values range between $\sim 3$ and $\sim 9 \mathrm{~m} \mathrm{~s}^{-1}$ for both nontornadic storms and F0-F1 tornadoes, while F2+ tornadoes occur in environments with slightly higher low-level shear $\left[\sim 6\right.$ to $\sim 12 \mathrm{~m} \mathrm{~s}^{-1}$ of $0-1-\mathrm{km}$ shear $(25$ th and 75 th percentiles)].

The findings obtained from the aforementioned prior studies targeting a variety of geographical regions suggest that although there are some ingredients of convective 
storm environments common to all regions [e.g., no matter what the region, convective storms require convective available potential energy (CAPE)], there are also considerable regional differences in the magnitudes of some of the most popular parameters used in convective storm forecasting owing to contrasting climatological and perhaps topographical characteristics.

This study is motivated by the fact that no prior studies, even those that have covered most of Europe, have investigated convective storm environments in Turkey. No environmental conditions are studied for the Middle East or for most of the Mediterranean countries as well. The data and methods used in the study are described in section 2. The distributions of environmental parameters calculated for observed tornado, waterspout, and severe hail cases are presented in section 3. Because of the lack of a severe windstorm database in Turkey, severe wind environments are not included in the study (an effort on building a severe wind database is under way). Finally, some conclusions appear in section 4 .

\section{Data and methods}

A severe weather database for Turkey has been built in recent years using official and unofficial records from a wide variety of sources. Tornado (including waterspouts) and severe hail (hail with a diameter of at least $1.5 \mathrm{~cm}$ ) records from the database are used as severe weather observations in this study. [See Kahraman and Markowski (2014) and Kahraman et al. (2016) for the details of the tornado and severe hail dataset, as well as climatologies for Turkey; see Tilev-Tanriover et al. (2015) for a thunderstorm climatology of the country. The group is also working on collecting severe wind data for use in future studies.] The geographical distribution of tornado and severe hail cases in Turkey indicates different characteristics in terms of regionality and intensity contrasts (Fig. 1). Tornadoes are more common in coastal regions, partially owing to a high number of waterspouts, especially around Antalya. On the other hand, severe hail is common in the west and parts of the interior. The relative maxima in the metropolitan areas (e.g., Istanbul, Ankara, and Izmir) strongly suggest a population bias and an underreporting of events in the more sparsely populated areas. (In spite of the likely underreporting in general, high severe hail and tornado frequencies have been diagnosed in some rural areas in southeastern and eastern Turkey, respectively.) Although the database contains records going back as far as the early nineteenth century, data from recent years are assumed to be more representative given the greater availability of reports and active efforts at documenting actual weather events, which are used in Fig. 1.
Turkey has eight active stations (one of which has data for only a few recent years) collecting radiosonde observations twice each day, with an average spacing of approximately $500 \mathrm{~km}$. There are almost always representativeness questions when using observed soundings to characterize the environments of convective storms (Davies-Jones 1993; Brooks et al. 1994; Grünwald and Brooks 2011); in addition, the complex topography of Turkey, the proximity of much of Turkey to large bodies of water, and highly variable low-level mesoscale and microscale wind fields present additional challenges. The limited number of severe weather occurrences in proximity to the radiosonde stations in space and time, in addition to the representativeness issues, motivate our use of soundings obtained from a reanalysis dataset rather than observed soundings. Soundings obtained from reanalysis data are not free of issues, however. One well-known shortcoming is the poor representation of capping inversions, which stems from the relatively coarse vertical resolution (Brooks et al. 2003; Grünwald and Brooks 2011).

The proximity soundings used in this study were obtained from the European Centre for Medium-Range Weather Forecasts interim reanalysis (ERA-Interim), which goes back to 1979 (Dee et al. 2011). Analyses are available every $12 \mathrm{~h}$ along with forecasts with 3 -h intervals. The horizontal grid spacing is $0.75^{\circ}$, and there are 28 vertical levels, consisting of one surface level and 27 pressure levels from 1000 to $100 \mathrm{hPa}$. The data used in this study cover the 35-yr period from 1 January 1979 to 31 December 2013. NCAR Command Language (NCL) is used for calculations of parameters from the reanalysis data (NCAR 2014).

A comparison of ERA-Interim data with 1200 UTC radiosonde observations in Turkey (from the Ankara, Istanbul, Izmir, Adana, Isparta, Samsun, and Diyarbakir stations) for 2005-13 has been done in terms of surfacebased CAPE and 0-6-km bulk shear for thunderstorm days. A total of 1592 soundings have been extracted from the reanalysis dataset, using the nearest grid point to the station. Results indicate a negative bias for both CAPE $\left(-93 \mathrm{~J} \mathrm{~kg}^{-1}\right.$ mean error) and shear $\left(-3.4 \mathrm{~m} \mathrm{~s}^{-1}\right.$ mean error) values. The low-level wind speed is underestimated in ERA-Interim, which agrees with lower shear values. Correlations for the surface-based CAPE and $0-6-\mathrm{km}$ bulk shear are 0.5 and 0.7 , respectively. Another study for central Europe gave correlations of ERA-Interim versus observations there were as low as 0.5 for CAPE and 0.9 for deep-layer shear (Westermayer et al. 2016).

Table 1 shows the groups of soundings analyzed and the number of cases for each category (1979-2013). "Likely mesocyclonic," "likely nonmesocyclonic," and 


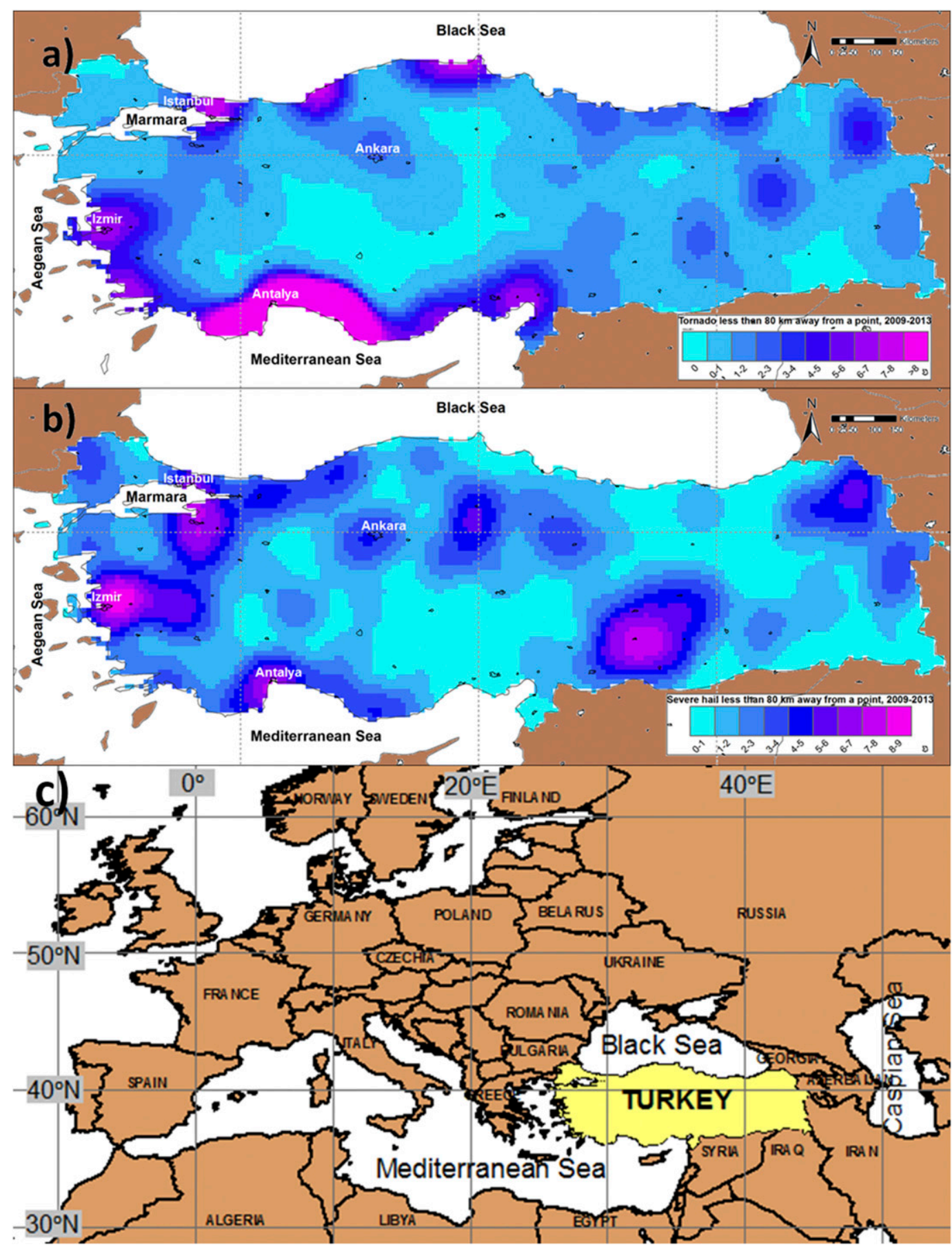

FIG. 1. Numbers of (a) tornado and (b) severe hail cases less than $\sim 80 \mathrm{~km}$ from a given point, between 2009 and 2013. Kernel density estimation with a search radius of $1.0^{\circ}$ and output cell size of $0.1^{\circ}$ was used, and over $192 \times 63$ grids were used for mapping the distributions. (The search radius was varied between $0.5^{\circ}$ and $1.5^{\circ}$, which does not change the pattern dramatically.) Urban areas are surrounded by black contours. (c) Location of Turkey.

"unknown" tornado classifications are described by Kahraman and Markowski (2014), aiming at distinguishing supercellular tornadoes from others when possible (for cases without enough confidence, the "unknown" category is introduced). For a few cases, Doppler radar imagery was used for a velocity couplet and/or reflectivity patterns like hook echoes or bounded weak-echo regions for discrete storms. For some others, 
TABLE 1. Severe weather categories used for the analysis (233 tornado cases and 319 severe hail cases).

\begin{tabular}{llr}
\hline \hline Category & \multicolumn{1}{c}{ Definition } & No. of samples \\
\hline TOR-sup & Likely mesocyclonic tornado cases (i.e., associated with supercells) & 33 \\
TOR-non & Likely nonmesocyclonic tornado cases (i.e., mostly waterspouts) & 68 \\
TOR-unk & Unknown tornado cases (tornadoes without enough confidence to fit & into one of the TOR-sup/TOR-non categories) \\
TOR-F2+ & Significant tornado cases (i.e., F2 or stronger, regardless of mesocyclonic, \\
& nonmesocyclonic, or unknown nature) & 28 \\
HAIL-lar & Large hail cases (1.5-4.5-cm diameter in the longest direction; i.e., \\
hAIL-vlg & hazelnut size or larger, but smaller than egg size) \\
& Very large hail cases (equal to or larger than $\sim 4.5-\mathrm{cm}$ diameter; i.e., \\
SUP & egg size or larger) & 282 \\
\hline
\end{tabular}

severe weather reports (e.g., very large hail) from tornadic storms were useful. Furthermore, satellite images and photographs/videos indicating mesocyclonic structures or nonmesocyclonic features (e.g., a number of stationary and nonthreatening waterspouts depicting a line parallel to a coast) were used to determine the category, if possible. Severe hail cases are classified as either "large hail" cases (diameters between 1.5 and $4.5 \mathrm{~cm}$ ) or "very large hail" cases (diameters $>4.5 \mathrm{~cm}$ ). The supercell category comprises very large hail cases without any tornado reports.

Deep moist convection requires conditionally unstable lapse rates (at least, on average, through a large depth of the troposphere), enough moisture for a parcel to have a level of free convection (LFC), and a lifting mechanism for the parcel to reach its LFC (Doswell et al. 1996). CAPE is the result of the first two ingredients. CAPE can be computed by lifting an air parcel from the surface, some altitude above the surface, or by lifting an air parcel possessing the mean thermodynamic characteristics of a layer. Soundings with most unstable CAPE (MUCAPE) less than $50 \mathrm{~J} \mathrm{~kg}^{-1}$ are excluded from the study ( 80 soundings in total), and in the supercell, mesocyclonic tornado, and F2+ tornado categories, soundings with negative storm-relative helicity (SRH) were excluded. Such soundings are assumed to be unrepresentative of the storm environment, based on our understanding that convective storms require buoyancy, cyclonically rotating updrafts require positive $\mathrm{SRH}$, and strong tornadoes are almost always associated with mesocyclones. ${ }^{1}$ It is possible (perhaps even likely)

\footnotetext{
${ }^{1}$ Though it is theoretically possible for large negative SRH to be associated with a strong anticyclonic tornado occurring within an anticyclonically rotating supercell storm, such occurrences are extremely rare worldwide. The diagnosis of a large negative SRH value near a significant tornado is believed to be much more likely an indication of an unrepresentative sounding than the occurrence of an anticyclonically rotating supercell producing an anticyclonic significant tornado.
}

that some left-moving supercells have been excluded, but given the lack of radar data accompanying the reports, we had no way of segregating right and left movers, and felt it was preferable to not risk having fundamentally different environments grouped together in the same bin. Overall, calculations of environmental parameters are performed for 233 tornado and 319 severe hail cases within the 35 -yr period.

A comparison of lifting condensation levels (LCLs) of surface parcels and parcels characterized by the mean properties of the lowest $100 \mathrm{hPa}$ (approximately $1000 \mathrm{~m}$ ) suggests that the latter is more representative of observed convective cloud bases (Craven et al. 2002), at least for the U.S. Great Plains. For this study, in addition to the surface level (and MUCAPE), mean layers of 200-, 500-, and 1000-m depth are used for calculation of environmental parameters such as CAPE and LCL [only surface-based CAPE (SBCAPE) and mixed layer CAPE (MLCAPE) for 200 and $1000 \mathrm{~m}$ are discussed].

\section{Analysis of parameters derived from ERA-Interim}

\section{a. Measures of instability}

Turkish severe storm environments are found to be associated with CAPE of up to $2000 \mathrm{~J} \mathrm{~kg}^{-1}$ for surfacebased parcels, with CAPE decreasing as the depth of the layer used to characterize the lifted parcel increases, as expected (Fig. 2). Tornado environments in Turkey have CAPE distributions similar to or slightly larger than the tornado environments documented in Poland having surface temperatures exceeding $18^{\circ} \mathrm{C}$ (Taszarek and Kolendowicz 2013), the F2+ tornado environments documented in central Europe (Púčik et al. 2015), the waterspouts environments in the eastern Adriatic Sea (Renko et al. 2016), and the tornado environments documented in the Kaltenböck et al. (2009) study that 

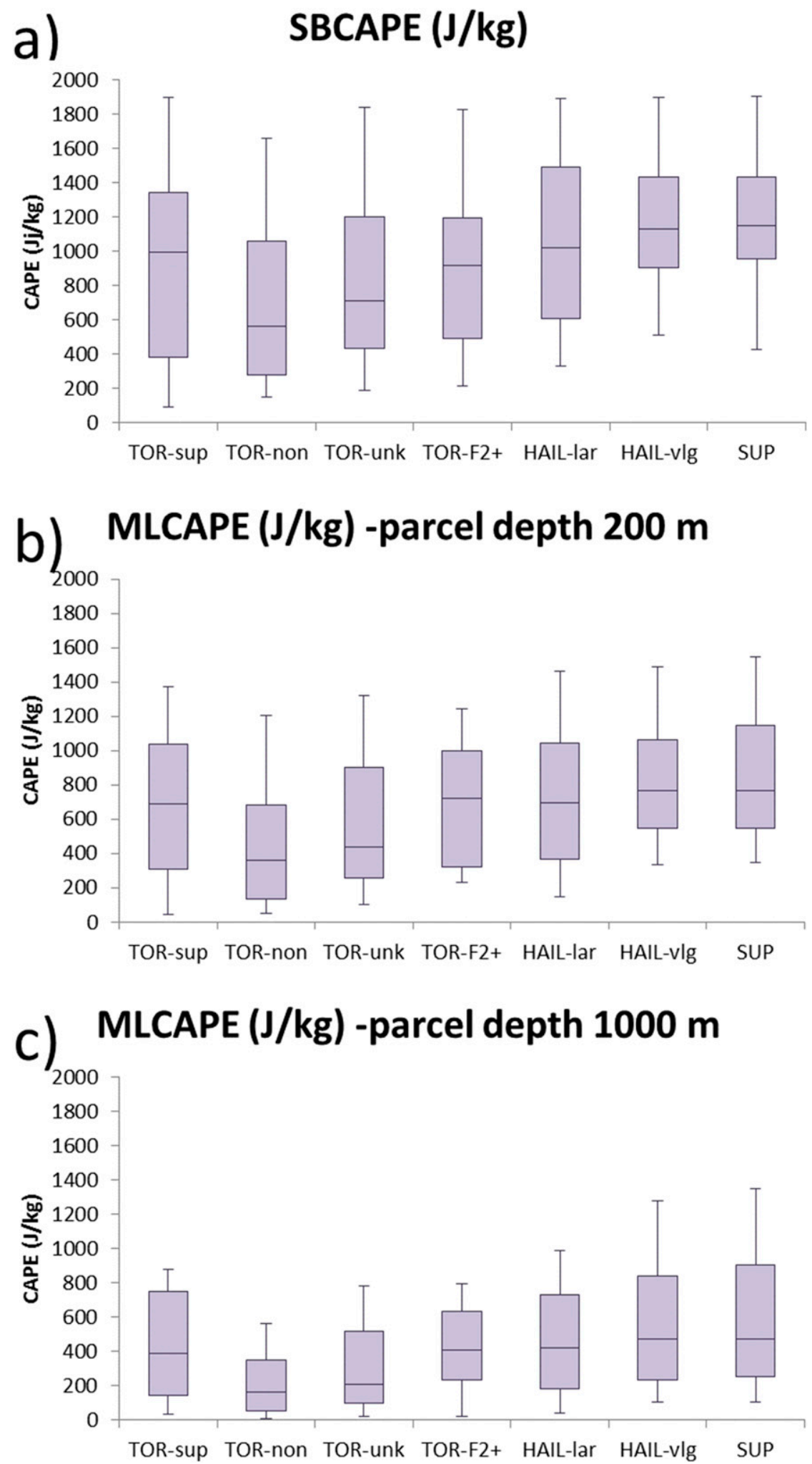

FIG. 2. CAPE of (a) surface parcel, (b) mixed layer parcel of 200-m depth, and (c) mixed layer parcel of 1000-m depth, for TOR-sup, TOR-non, TOR-unk, TOR-F2+, large hail (HAIL-lar, hail with a diameter of $\sim 1.5$ to $\sim 4.5 \mathrm{~cm}$ ), HAIL-vlg, and SUP. The boxes extend to the 25 th and 75 th percentiles, while the whiskers reach to the 10th and 90th percentiles. Median values are shown within the boxes. 


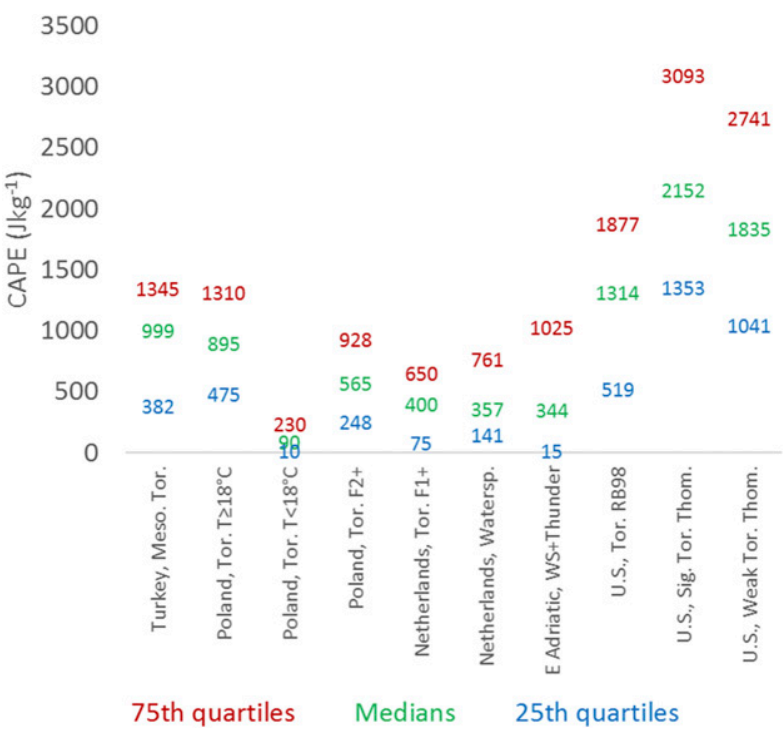

FIG. 3. Comparison of CAPE (SBCAPE, except for the U.S. studies, which are calculated for a 1000-m mixed layer) distributions of tornado soundings from different studies. The red values indicate the 75th quartiles, the green values indicate the median values, and the blue values indicate the 25 th percentiles of mesocyclonic tornadoes in Turkey as presented in this study (Turkey, Meso. Tor.), tornadoes with a surface temperature of $18^{\circ} \mathrm{C}$ or higher in Poland (Poland, Tor. $T \geq 18^{\circ} \mathrm{C}$ ), tornadoes with a surface temperature lower than $18^{\circ} \mathrm{C}$ in Poland (Poland, Tor. $T<18^{\circ} \mathrm{C}$ ), F2 + tornadoes in Poland (Poland, Tor. F2+), F1+ tornadoes in the Netherlands (Netherlands, Tor. F1+), waterspouts in the Netherlands (Netherlands, Watersp.), waterspouts with thunderstorms in the eastern Adriatic (E Adriatic, WS+Thunder), tornadoes in the United States (U.S., Tor. RB98) [RB98 refers to the Rasmussen and Blanchard (1998) study], significant tornadoes in the United States (U.S., Sig. Tor. Thom.) [Thom. refers to the Thompson et al. (2003) study], and weak tornadoes in the United States (U.S., Weak Tor. Thom.).

covered most of Europe (Fig. 3). CAPE in Turkish tornado environments (with SBCAPE medians of $998.7 \mathrm{~J} \mathrm{~kg}^{-1}$ for TOR-sup, $564.2 \mathrm{~J} \mathrm{~kg}^{-1}$ for TOR-non, and $710.3 \mathrm{~J} \mathrm{~kg}^{-1}$ for TOR-unk; see Table 1 for TOR category definitions) is much larger than the CAPE values in tornado environments in Poland characterized by surface temperatures less than $18^{\circ} \mathrm{C}$ (Taszarek and Kolendowicz 2013), F2 + tornado environments in Poland (Taszarek and Kolendowicz 2013), Dutch tornado and waterspout environments (Groenemeijer and Van Delden 2007), and weak tornadic storm environments in central Europe (Púčik et al. 2015), which all have less than $500 \mathrm{~J} \mathrm{~kg}^{-1}$ median values (Fig. 3). However, CAPE is considerably less, on average, than in the U.S. Great Plains tornadic storm environments (e.g., Rasmussen and Blanchard 1998; Thompson et al. 2003). The differences with European countries might partially be attributed to the lower latitude of Turkey as well as surrounding warmer seas, as higher temperature and moisture content more frequently exist at low levels in Turkey, despite higher elevations in most parts of the country. An average sea surface temperature (SST) of $21.22^{\circ} \mathrm{C}$ is observed across the eastern Mediterranean (Levantine) between 1982 and 2012, which is the highest among the sections of the Mediterranean Sea (Shaltout and Omstedt 2014). The Black Sea and Aegean Sea average SSTs are $17.97^{\circ}$ and $19.05^{\circ} \mathrm{C}$, respectively (Shaltout and Omstedt 2014). However, the low-level moisture supplied by the bodies of water in Turkey's proximity is less than that provided to the U.S. Great Plains region by the Gulf of Mexico owing to the warmer water temperatures of the Gulf of Mexico. (An average SST of $26.5^{\circ} \mathrm{C}$ is observed in the Gulf between 1985 and 2016, according to NOAA's Atlantic Oceanographic and Meteorological Laboratory/Physical Oceanography Division.)

Nonmesocyclonic tornadoes in Turkey (TOR-non), which are mostly waterspouts along the coasts, tend to form in lower-CAPE environments compared to mesocyclonic tornadoes (TOR-sup in Fig. 2). Tornadoes without enough confidence to be classified as mesocyclonic or nonmesocyclonic (TOR-unk) are associated with intermediate CAPE values. Also, waterspouts do not always require high CAPE values, as they may occur with shallow cloud depths even without thunder. Although these findings are meaningful, CAPE cannot be used as a discriminator between mesocyclonic and nonmesocyclonic convection, because of the large overlap between categories.

For large hail occurrences, CAPE (both SBCAPE and MLCAPE) is usually higher than that of other storm environments (Fig. 2). Although CAPE is not a good discriminator itself for a severe storm environment, severe hail being associated with high CAPE (when together with high shear) is consistent with the literature. The large hail, very large hail, and supercell CAPE results are comparable to those in Finland (Tuovinen et al. 2015), southwest Europe (Merino et al. 2013), central Europe (Púčik et al. 2015), the Netherlands (Groenemeijer and Van Delden 2007), and much of Europe (Kaltenböck et al. 2009); but again, they are lower than U.S. values (Rasmussen and Blanchard 1998; Thompson et al. 2003; Johnson and Sugden 2014), as seen in Fig. 4.

Low-level lapse rates (from the surface to $3000 \mathrm{~m}$ AGL) are similar across all tornado environments (i.e., TOR-non, TOR-sup, TOR-unk, and TOR-F2+; Fig. 5a). However, the 850-700-hPa layer is substantially less unstable in TOR-non environments, compared to other tornado categories (Figs. 5b,c). This difference also explains the aforementioned lower CAPE. There is not a strong signal in lapse rates for significant tornadoes (TOR-F2+), as they span a similar range of values when 


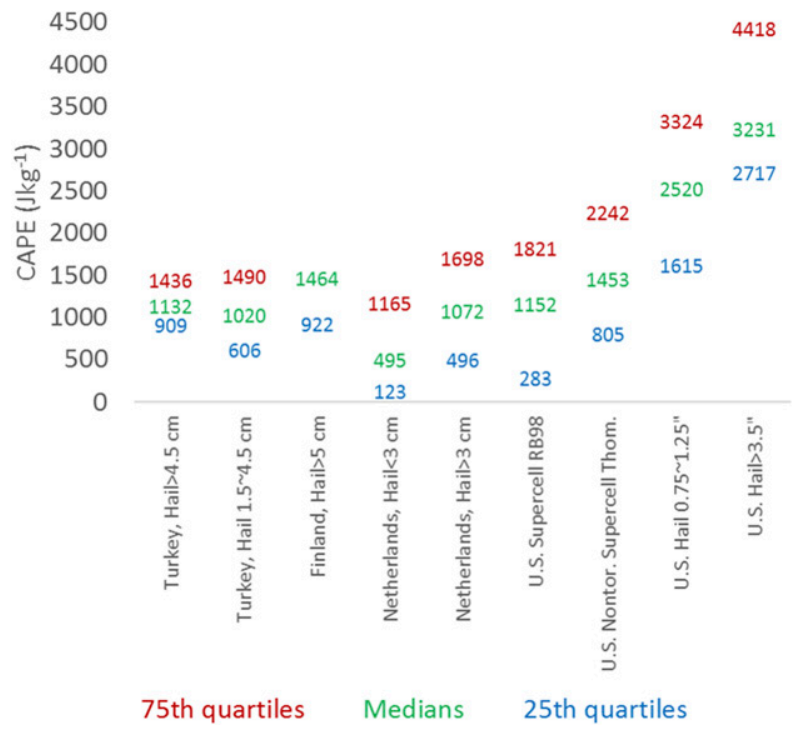

FIG. 4. As in Fig. 3, but for severe hail and supercell soundings. "Turkey, Hail $>4.5 \mathrm{~cm}$ " refers to very large hail in Turkey, "Turkey, Hail $1.5 \sim 4.5 \mathrm{~cm}$ " refers to large hail in Turkey, "Finland, Hail $>5 \mathrm{~cm}$ " refers to significant hail in Finland, "Netherlands, Hail $<3 \mathrm{~cm}$ " refers to hail smaller than $3 \mathrm{~cm}$ in the Netherlands, "Netherlands, Hail $>3 \mathrm{~cm}$ " refers to hail equal to or larger than $3 \mathrm{~cm}$ in the Netherlands, "U.S. Supercell RB98" refers to supercells in the United States, "U.S. Nontor. Supercell Thom." refers to nontornadic supercells in the United States, "U.S. Hail $0.75 \sim 1.25$ in." refers to hail of $0.75-1.25$-in. size in the United States, and "U.S. Hail > 3.5 in." refers to hail larger than 3.5 in. in the United States.

compared with TOR-sup and TOR-unk tornadoes. However, large and very large hail cases as well as supercell environments have slightly higher values than do other storm categories. Again, this contributes to slightly higher CAPE for severe hail environments, compared to other environments. The differences between the large and very large categories are negligible.

\section{b. Parameters related to vertical wind shear}

In the Rasmussen and Blanchard (1998) study, proximity soundings obtained near observed U.S. tornadic and nontornadic supercells had median $0-6-\mathrm{km}_{\mathrm{shear}}{ }^{2}$ values of 19.1 and $18.4 \mathrm{~s}^{-1}$, respectively (Fig. 6). In another U.S. study, one that relied on RUC soundings, slightly higher $0-6-\mathrm{km}$ shear values were found, with median values of $24.5 \mathrm{~m} \mathrm{~s}^{-1}$ for significant tornadoes, $22.5 \mathrm{~m} \mathrm{~s}^{-1}$ for weak tornadoes, and $22.1 \mathrm{~m} \mathrm{~s}^{-1}$ for

\footnotetext{
${ }^{2}$ The 0-6-km shear in the Rasmussen and Blanchard (1998) study was really the magnitude of the vector wind difference between the mean wind in the lowest $500 \mathrm{~m}$ and the $6 \mathrm{~km}$ AGL wind, which they referred to as the BL-6-km shear ("BL" stands for boundary layer). These shear magnitudes would tend to be slightly less than the $0-6-\mathrm{km}$ shear.
}

nontornadic supercells (Thompson et al. 2003). Lesser deep-layer shear values have been found, however, in prior studies of European supercell environments, as shown for central Europe (Púčik et al. 2015), with a $22 \mathrm{~m} \mathrm{~s}^{-1}$ median for significant tornadoes; the Netherlands, with 17.0, 15.3, and $27.0 \mathrm{~m} \mathrm{~s}^{-1}$ medians for F0, F1, and F2 tornadoes, respectively (Groenemeijer and Van Delden 2007); and Poland, with unrated, F0/F1, and F2/F3 tornadoes having median shears of 15.8, 18.9, and $25.2 \mathrm{~m} \mathrm{~s}^{-1}$, respectively (Taszarek and Kolendowicz 2013).

In Turkey, 0-6-km shear in environments associated with TOR-sup $\left(21.9 \mathrm{~m} \mathrm{~s}^{-1}\right.$ median value, with 26.2 and $14.0 \mathrm{~m} \mathrm{~s}^{-1}$ for the 75 th and 25 th percentiles, respectively) is similar to the shear that has been found in prior studies of European supercell environments (Fig. 7a). The TOR$\mathrm{F} 2+\left(21.6 \mathrm{~m} \mathrm{~s}^{-1}\right.$ median value $)$ and TOR-unk $\left(18.6 \mathrm{~m} \mathrm{~s}^{-1}\right.$ median value) categories are not distinguishable from mesocyclonic tornadoes in terms of $0-6-\mathrm{km}$ shear. As expected, TOR-non events occur in environments having much less 0-6-km shear compared to the environments of other storms (12.1 $\mathrm{m} \mathrm{s}^{-1}$ median value).

In Fig. 7a, a slight difference in deep-layer shear between the large and very large hail (as well as supercell) categories exists $\left(14.0,17.2\right.$, and $17.2 \mathrm{~m} \mathrm{~s}^{-1}$ median values), with very large hail (and supercells) showing higher values, closer to those of mesocyclonic tornado environments. This result is consistent with the idea that very large hail (egg size or larger) occurs mainly with supercells, which require large deep-layer shear.

In Turkey, based on the proximity soundings obtained from the ERA-Interim data, the 0-1-km shear for all environments is relatively weak, similar to the aforementioned studies for Poland and central Europe (Fig. 7b). The F2+ tornadoes occur in low-level shear environments not distinguishable from mesocyclonic or unknown tornadoes, though the median value and lower percentiles appear to be slightly higher than other storm categories. These results are below the observed lowlevel shear environments of tornadic supercells in the United States, and can at least partially be attributed to the questionable representativeness of the low-level winds in reanalysis data around the very complex terrain of Turkey. Nevertheless, compared with each other, mesocyclonic tornadoes, unknown-category tornadoes, and $\mathrm{F} 2+$ tornadoes have stronger low-level shear environments than those of nonmesocyclonic tornadoes, large hail, and very large hail.

$\mathrm{SRH}$, for cyclonically rotating, right-moving supercells, is calculated for the $0-3-$ and $0-1-\mathrm{km}$ layers (Fig. 8). In Turkey, the highest $0-3-\mathrm{km}$ SRH values are associated with $\mathrm{F} 2+$ tornadoes, mesocyclonic tornadoes, very large hail, and supercells. The 90th percentile values exceed $1000 \mathrm{~m}^{2} \mathrm{~s}^{-2}$; thus, tornadic supercells in 

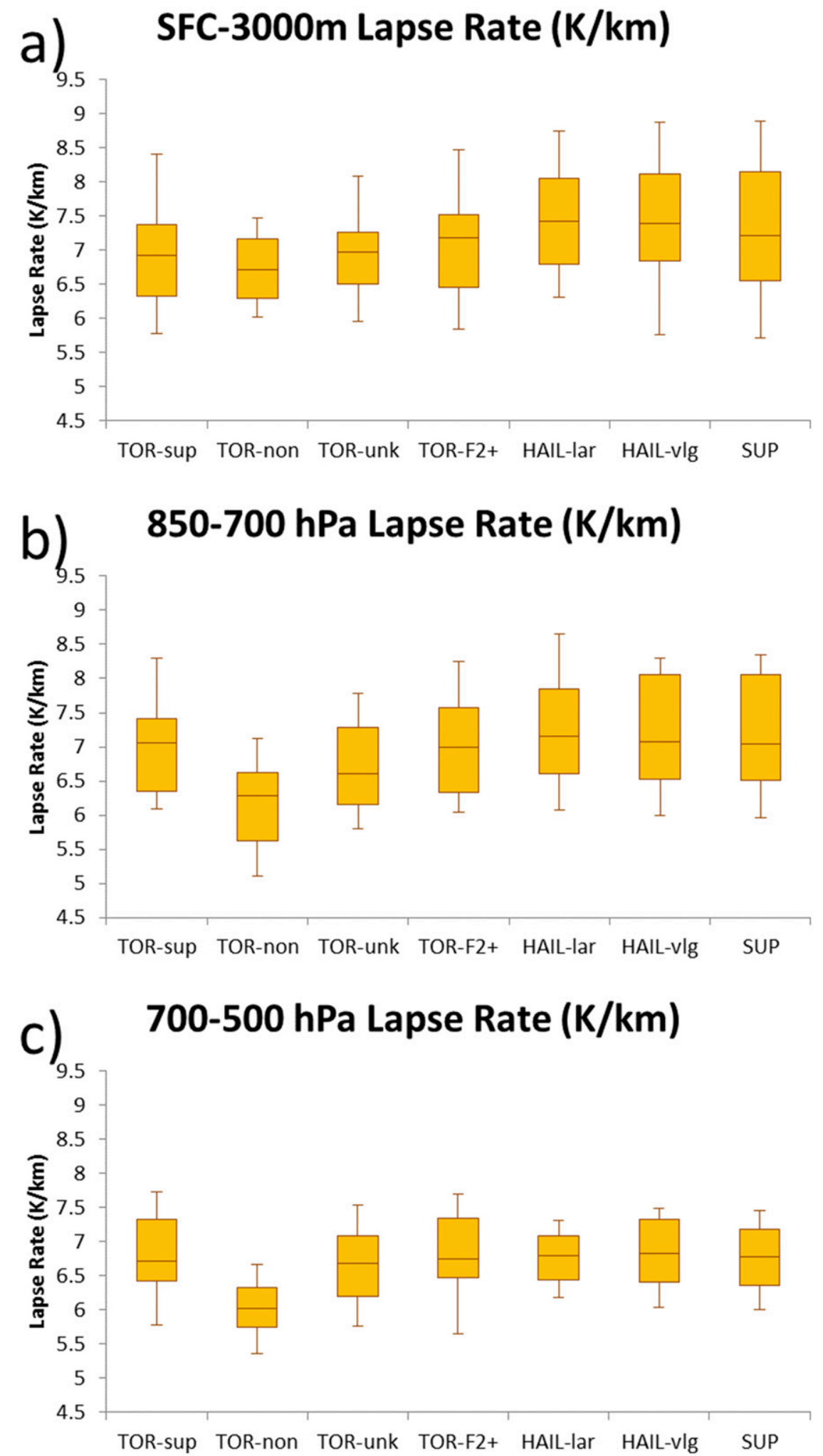

FIG. 5. As in Fig. 2, but for lapse rates of (a) from the surface to $3000 \mathrm{~m}$ AGL, (b) the 850-700-hPa layer, and (c) the 700-500-hPa layer. 


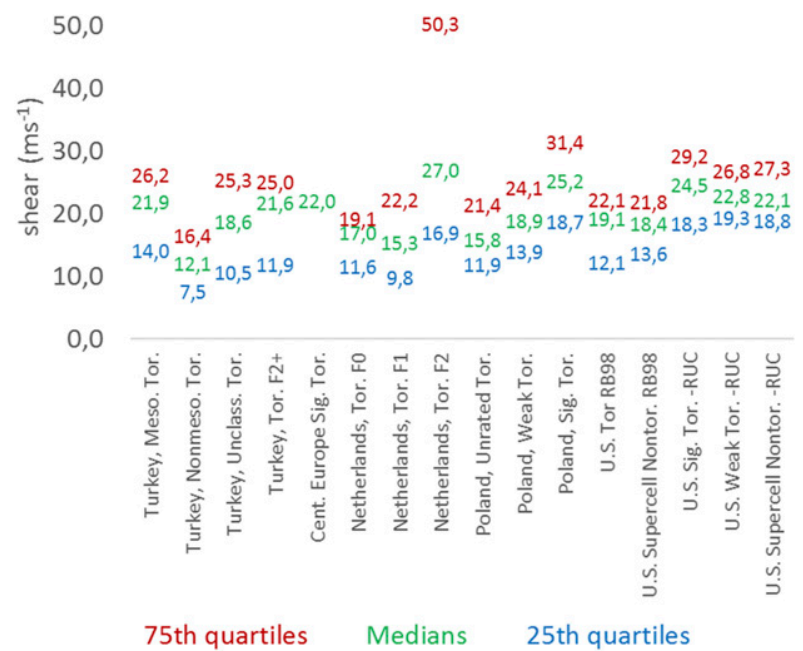

FIG. 6. As in Fig. 3, but for deep-layer shear (0-6-km bulk shear for all, except for the Rasmussen and Blanchard (1998) study (RB98), which uses BL 6-km shear, with BL defined as the 0-500-m boundary layer). "Turkey, Meso. Tor." refers to mesocyclonic tornadoes in Turkey, "Turkey, Nonmeso. Tor." refers to nonmesocyclonic tornadoes in Turkey, "Turkey, Unclass. Tor." refers to tornadoes in Turkey without mesocyclonic/nonmesocyclonic classification, "Turkey, Tor. F2+" refers to F2+ tornadoes in Turkey, "Cent. Europe Sig. Tor." refers to significant tornadoes across central Europe, "Netherlands, Tor. F0" refers to F0 tornadoes in the Netherlands, "Netherlands, Tor. F1" refers to F1 tornadoes in the Netherlands, "Netherlands, Tor. F2" refers to F2 tornadoes in the Netherlands, "Poland, Unrated Tor." refers to unrated tornadoes in Poland, "Poland, Weak Tor." refers to weak tornadoes in Poland, "Poland, Sig. Tor." refers to significant tornadoes in Poland, "U.S. Tor RB98" refers to tornadoes in the United States, "U.S. Supercell Nontor. RB98" refers to nontornadic supercells in the United States, "U.S. Sig. Tor. -RUC" refers to significant tornadoes in the United States (RUC soundings), "U.S. Weak Tor. -RUC" refers to weak tornadoes in the United States (RUC soundings), and "U.S. Supercell Nontor. -RUC" refers to nontornadic supercells in the United States (RUC soundings).

Turkey occasionally are associated with environments containing extreme $\mathrm{SRH}$, as has been noted in the United States (Rasmussen and Blanchard 1998; Thompson et al. 2003). Such large values have not previously been documented in tornadic supercell environments elsewhere in Europe, however (Kaltenböck et al. 2009; Merino et al. 2013; Púčik et al. 2015).

SRH in the $0-1-\mathrm{km}$ layer, like $0-1-\mathrm{km}$ shear, is usually helpful in discriminating between environments conducive for significant tornadoes and environments supportive of only nontornadic supercells. The median $0-1-\mathrm{km}$ SRH for weak tornadoes in the United States is $137 \mathrm{~m}^{2} \mathrm{~s}^{-2}$ (Thompson et al. 2003); for F0, F1, and F2 tornadoes in the Netherlands the values are 27, 80, and $196 \mathrm{~m}^{2} \mathrm{~s}^{-2}$, respectively (Groenemeijer and Van Delden 2007); and for F0/F1 and F2/F3 tornadoes in Poland they are 87 and $113 \mathrm{~m}^{2} \mathrm{~s}^{-2}$, respectively (Taszarek and
Kolendowicz 2013). However, the median 0-1-km SRH in mesocyclonic tornado environments in Turkey is lower than most of these cases $\left(48.4 \mathrm{~m}^{2} \mathrm{~s}^{-2}\right)$, if not all (Fig. 8b), which is consistent with the previously noted lesser $0-1-\mathrm{km}$ shear values. The median $0-1-\mathrm{km}$ SRH of environments supportive of $\mathrm{F} 2+$ tornadoes exceeds the median $0-1-\mathrm{km}$ SRH of the other storm categories, however; the 90th percentile values exceed $250 \mathrm{~m}^{2} \mathrm{~s}^{-2}$ in the environments of both mesocyclonic tornadoes and F2+ tornadoes. The negative SRH values for the TOR-non and TOR-unk categories can be considered indicative of nonsupercell processes for these classifications.

\section{c. Lifting condensation level}

The altitude of the LCL has been an important discriminator between tornadic and nontornadic supercells in the United States, given that a supercell exists and other environmental conditions are favorable (e.g., lowlevel shear is strong), with relatively low LCLs favoring tornadic supercells (Rasmussen and Blanchard 1998; Thompson et al. 2003). However, in other parts of the world, Turkey included, LCLs have been found to have limited utility as a tornadic versus nontornadic supercell discriminator because LCLs tend to have much less variability on severe storms days than in the United States. (LCLs in Europe are almost always low in comparison to LCLs across the Great Plains region, especially the western Great Plains.) For example, in the Netherlands, LCLs contribute practically no forecast skill to the discrimination of tornadic versus nontornadic storms (Groenemeijer and Van Delden 2007). In Poland, stronger tornadoes occurred in slightly higher LCLs than weaker tornadoes, but the median LCLs of both environments are below $1000 \mathrm{~m}$ (Taszarek and Kolendowicz 2013).

The distributions of LCLs, calculated by lifting surface parcels as well as parcels possessing the mean thermodynamic characteristics of the lowest $500 \mathrm{~m}$, imply that convective cloud bases in Turkey are usually below $1000 \mathrm{~m}$ in tornadic storm environments (Fig. 9). Nontornadic environments reveal higher medians and upper percentiles, but they are generally still below $1500 \mathrm{~m}$. The tornadic supercell LCL distributions are narrower than the nontornadic supercell LCL distributions.

\section{d. Composite indices}

Composite indices combine multiple parameters (often a measure of instability is combined with a measure of the vertical wind shear) in an empirical way in order to help forecasters identify environments that are favorable for a certain storm type or hazard better than a single parameter might be able to. For example, neither CAPE nor shear alone indicates the potential for 

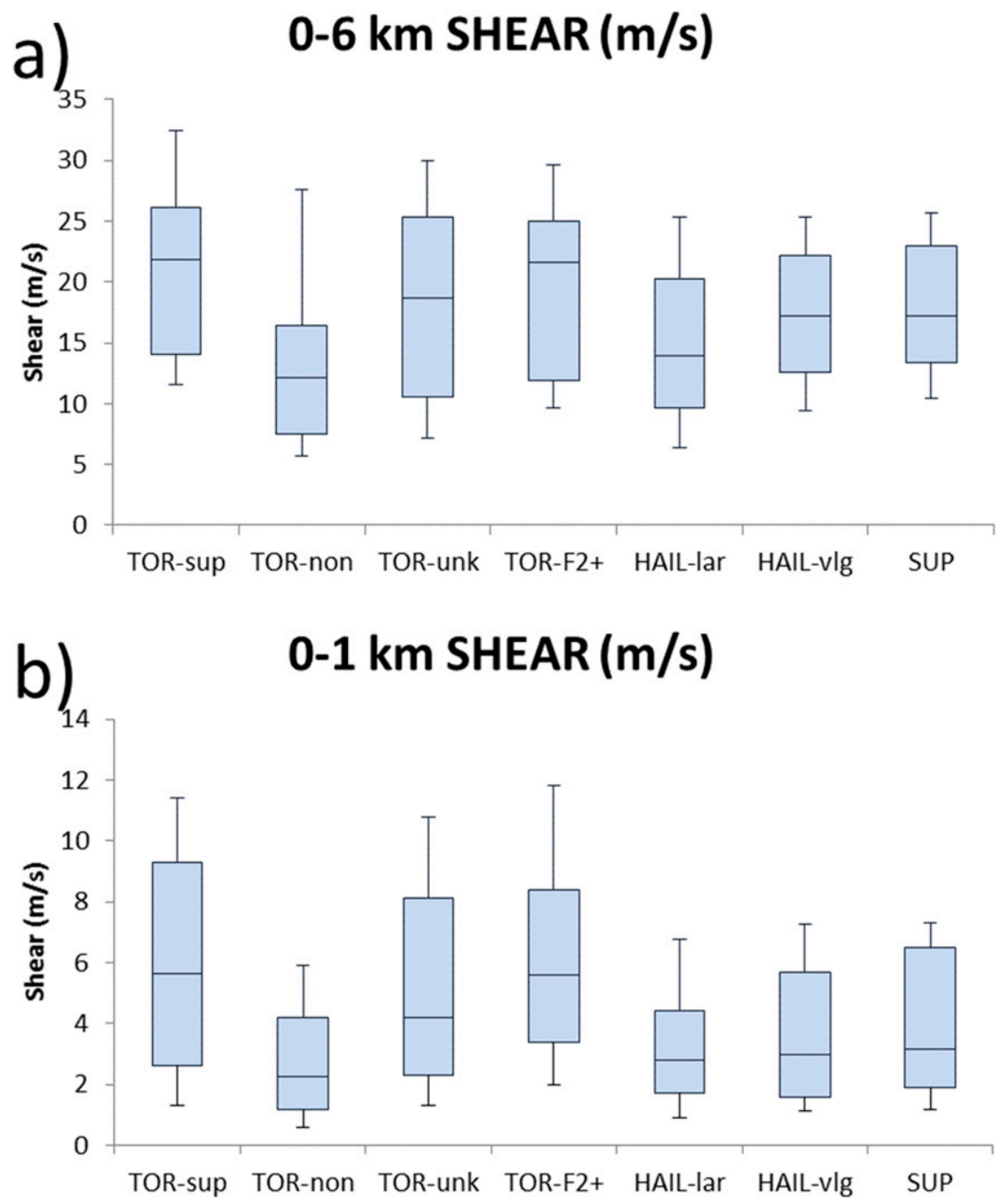

FIG. 7. As in Fig. 2, but for bulk shear for (a) the layer between the surface and $6 \mathrm{~km}$ AGL and (b) the layer between the surface and $1 \mathrm{~km}$ AGL.

supercell storms, but the collocation of CAPE and strong shear is a strong indication of the possibility of supercell storms, given convective initiation.

One of the composite indices is the energy-helicity index (EHI), which combines CAPE and storm-relative helicity (Hart and Korotky 1991; Davies-Jones 1993). It is formulated as

$$
\mathrm{EHI}=\frac{\mathrm{CAPE} \times \mathrm{SRH}}{160000} .
$$

EHI is usually calculated using the SRH measured in the 0-3- and 0-1-km layers. In the United States, the median EHI values obtained from the 0-3-km SRH (EHI03) for nontornadic and tornadic supercells were 0.64 and 1.48 , respectively, in the Rasmussen and Blanchard (1998) study, while ordinary storm environments had a median
EHI03 of just 0.14 . Thompson et al.'s study found a median EHI calculated with 0-1-km SRH (EHI01) of 2.1 for significant tornadoes, whereas it was 1.4 for weak tornadoes, 0.8 for nontornadic supercells, 0.5 for marginal supercells, and 0.1 for nonsupercells. On the other hand, this index has been found not to be useful in Europe, as in almost all environments, median EHI01 values are below 0.1 (Kaltenböck et al. 2009). In Turkey, reanalysisderived EHI (both) values for tornadic environments are much lower than those in the United States, but higher in than European environments (Figs. 10a,b). The very large hail environments-F2+ tornadic storm environments, supercells, and mesocyclonic tornado environments-have the highest values of EHI03 and EHI01 within all categories, which are comparable to U.S. environments except the latter (EHI01). In general, low EHI in Turkey can be attributed to both CAPE and 

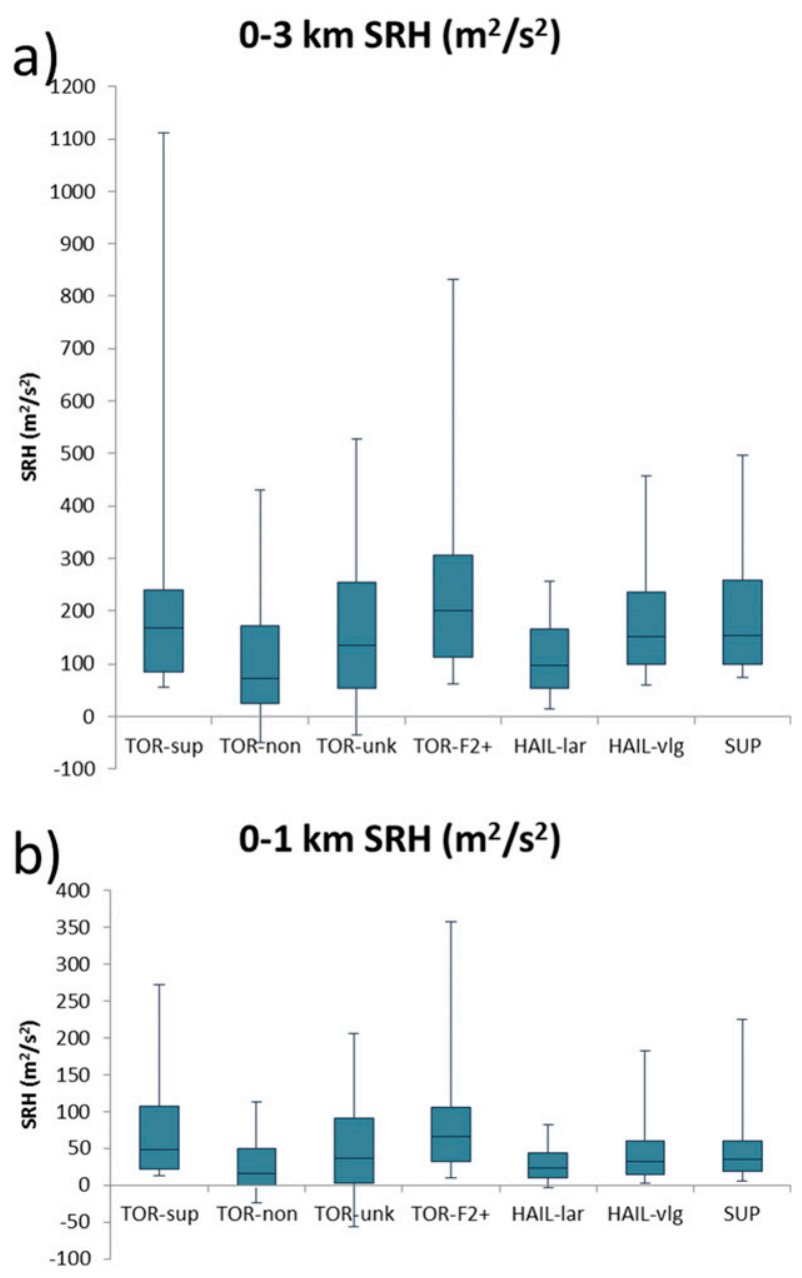

FIG. 8. As in Fig. 2, but for SRH calculated for right-moving supercells for the (a) 0-3- and (b) 0-1-km layers.

SRH being lower than in those in the United States. In particular, EHI01 reflects the low SRH01 (and, therefore, 0-1-km shear) magnitudes. Nevertheless, F2+ tornadoes have the highest EHI01, followed by mesocyclonic tornado environments.

Another composite index for supercell forecasting is the supercell composite parameter (SCP), which is the product of the CAPE of the MUCAPE, 0-3-km SRH (SRH03), and $0-6-\mathrm{km}$ shear (SH06). In this study the following equation is used for SCP (Thompson et al. 2004):

$$
\mathrm{SCP}=\frac{\text { MUCAPE }}{1000 \mathrm{~J} \mathrm{~kg}^{-1}} \times \frac{\mathrm{SRH} 03}{50 \mathrm{~m}^{2} \mathrm{~s}^{-2}} \times \frac{\mathrm{SH} 06}{20 \mathrm{~m} \mathrm{~s}^{-1}} .
$$

In Turkey, very large hail and supercell environments, followed by mesocyclonic tornado and F2+ tornado environments, have the highest SCP values. All of these environments have median values exceeding 2 (Fig. 10c). Large hail environments and environments in which
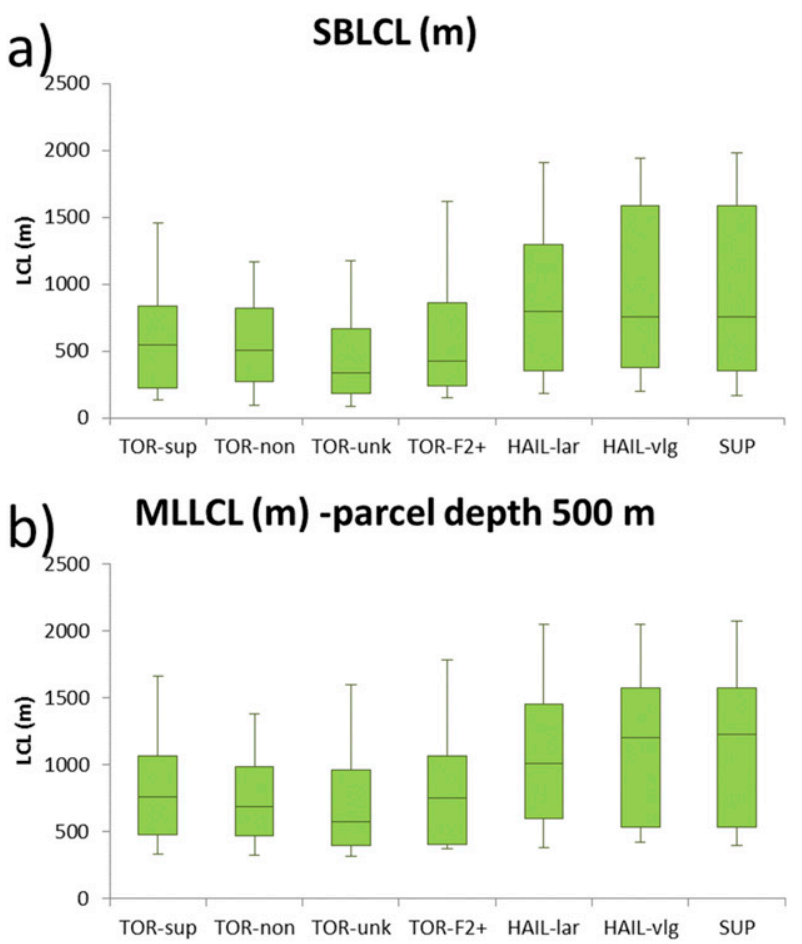

FIG. 9. As in Fig. 2, but for LCLs of the (a) surface-based parcel and (b) mixed layer parcel of 500-m depth.

tornadoes of unknown intensity have occurred have median SCP values of $\sim 1$. Nonmesocyclonic tornadoes, as expected, have the lowest SCP values.

The significant tornado parameter (STP) is an index developed to identify significant tornadic storm environments (Thompson et al. 2004). It combines SBCAPE and deep-layer shear (ingredients for supercells), in addition to SRH01 and LCL (ingredients for tornadoes) in the following manner:

$$
\begin{aligned}
\mathrm{STP}= & \frac{\mathrm{SBCAPE}}{1500 \mathrm{~J} \mathrm{~kg}^{-1}} \times \frac{2000-\mathrm{SBLCL}}{1000 \mathrm{~m}} \\
& \times \frac{\mathrm{SRH} 01}{150 \mathrm{~m}^{2} \mathrm{~s}^{-2}} \times \frac{\mathrm{SH} 06}{20 \mathrm{~m} \mathrm{~s}^{-1}} .
\end{aligned}
$$

Following Thompson et al. (2002, 2004), surface-based LCLs (SBLCLs) below $1000 \mathrm{~m}$ are limited to $1000 \mathrm{~m}$, and SBLCLs above $2000 \mathrm{~m}$ are capped at $2000 \mathrm{~m}$; 0 $6-\mathrm{km}$ shear is capped at $30 \mathrm{~m} \mathrm{~s}^{-1}$ and set to $0 \mathrm{~m} \mathrm{~s}^{-1}$ when less than $12.5 \mathrm{~m} \mathrm{~s}^{-1}$. STP exceeding 1 is commonly considered to be supportive of significant tornadoes in the United States (Thompson et al. 2004). However, owing to climatologically small $0-1-\mathrm{km}$ SRH and SBCAPE in Turkey relative to the United States, STP rarely exceeds 1 in Turkey (Fig. 10d). Nevertheless, F2+ tornado environments have the highest median STP 

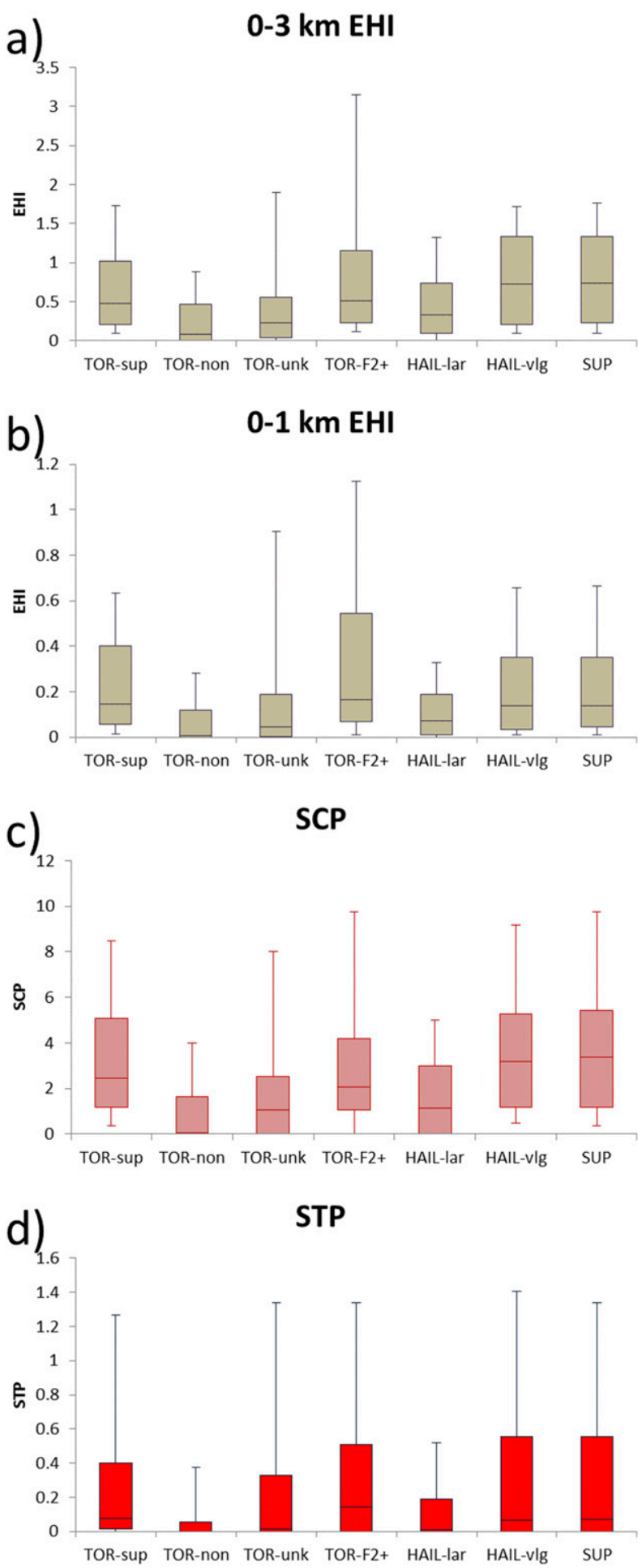

FIG. 10. As in Fig. 2, but for the following composite parameters:

(a) EHI for the 0-3-km layer, (b) EHI for the 0-1-km layer, (c) supercell composite parameter, and (d) significant tornado parameter. value out of all severe weather categories, and the median STP in nontornadic supercell environments is nearly zero.

\section{Conclusions}

The environments of severe convective storms in Turkey are characterized by approximately $500 \mathrm{~J} \mathrm{~kg}^{-1}$ larger CAPE on average than severe storm environments in the rest of Europe, probably at least in part because of the lower latitude and proximity to warm water. Turkish severe storm environments have roughly $500-1000 \mathrm{~J} \mathrm{~kg}^{-1}$ less CAPE than typical U.S. severe storm environments. For deep-layer shear, again Turkish values are up to $5 \mathrm{~m} \mathrm{~s}^{-1}$ lower than those in the United States, and similar to European environments. However, $\sim 2-4 \mathrm{~m} \mathrm{~s}^{-1}$ less low-level shear is present in Turkish tornadic supercell environments (and also other categories as well) than in tornadic supercell environments that have been studied in the Europe or the United States. This finding could be the result of limitations of obtaining proximity soundings from reanalysis data. We speculate that Turkey's complex topography might modify the low-level winds, creating locally more favorable severe storm environments than the environments depicted in the relatively smooth reanalysis fields, and low-level wind fields might be expected to be particularly susceptible to mischaracterization in the reanalysis datasets.

The LCL in Turkish severe storms environments is similar to the LCL documented in European environments, and LCLs in both regions are lower than in U.S. severe storm environments. However, tornadic LCL distributions are narrower than nontornadic distributions. SRH distributions are similar to those in Europe. Though the composite parameters EHI and SCP are not as high on average as in the United States (i.e., commonly used U.S. thresholds for such parameters would have to be modified for use in Turkey), EHI and SCP are still useful in segregating supercell [supercells without tornadoes but with very large hail (SUP), TOR-sup, and very large hail, with a hail diameter $\sim 4.5 \mathrm{~cm}$ or larger (HAIL-vlg)] and nonsupercell categories (e.g., TOR-non).

Acknowledgments. AK was supported by the Scientific and Technological Research Council of Turkey (TÜBİTAK), with Program 2214. He thanks the Department of Meteorology and Atmospheric Science at The Pennsylvania State University for hosting him between August 2013 and August 2014. George Bryan is acknowledged for his Fortran code for CAPE 
calculations, which is wrapped into an NCAR Command Language (NCL) script. The authors are also grateful for Istanbul Technical University's BAP program for supporting this study. Finally, we thank Matthew Bunkers, two anonymous reviewers, and Editor Pamela Heinselman for their comments and suggestions for improving the paper.

\section{REFERENCES}

Brooks, H. E., 2009: Proximity soundings for severe convection for Europe and the United States from reanalysis data. Atmos. Res., 93, 546-553, https://doi.org/10.1016/j.atmosres.2008.10.005.

_ C. A. Doswell III, and J. Cooper, 1994: On the environments of tornadic and nontornadic mesocyclones. Wea. Forecasting, 9, 606-618, https://doi.org/10.1175/1520-0434(1994)009<0606: OTEOTA $>2.0$.CO;2.

- J. W. Lee, and J. P. Craven, 2003: The spatial distribution of severe thunderstorm and tornado environments from global reanalysis data. Atmos. Res., 67-68, 73-94, https://doi.org/ 10.1016/S0169-8095(03)00045-0.

Bunkers, M. J., 2002: Vertical wind shear associated with leftmoving supercells. Wea. Forecasting, 17, 845-855, https:// doi.org/10.1175/1520-0434(2002)017<0845:VWSAWL>2.0.CO;2.

Craven, J. P., R. E. Jewell, and H. E. Brooks, 2002: Comparison between observed convective cloud-base heights and lifting condensation level for two different lifted parcels. Wea. Forecasting, 17, 885-890, https://doi.org/10.1175/ 1520-0434(2002)017<0885:CBOCCB > 2.0.CO;2.

Davies-Jones, R., 1993: Helicity trends in tornado outbreaks. Preprints, 17th Conf. on Severe Local Storms, St. Louis, MO, Amer. Meteor. Soc., 56-60.

Dee, D. P., and Coauthors, 2011: The ERA-Interim reanalysis: Configuration and performance of the data assimilation system. Quart. J. Roy. Meteor. Soc., 137, 553-597, https://doi.org/ 10.1002/qj.828.

Doswell, C. A., III, H. E. Brooks, and R. A. Maddox, 1996: Flash flood forecasting: An ingredients-based methodology. Wea. Forecasting, 11, 560-581, https://doi.org/10.1175/ 1520-0434(1996)011<0560:FFFAIB > 2.0.CO;2.

Dupilka, M. L., and G. W. Reuter, 2011: Composite soundings associated with severe and tornadic thunderstorms in central Alberta. Atmos.-Ocean, 49, 269-278, https://doi.org/10.1080/ 07055900.2011.607146.

Groenemeijer, P. H., and A. Van Delden, 2007: Sounding-derived parameters associated with large hail and tornadoes in the Netherlands. Atmos. Res., 83, 473-487, https://doi.org/10.1016/ j.atmosres.2005.08.006.

Grünwald, S., and H. E. Brooks, 2011: Relationship between sounding derived parameters and the strength of tornadoes in Europe and the USA from reanalysis data. Atmos. Res., 100, 479-488, https://doi.org/10.1016/j.atmosres.2010.11.011.

Hart, J. A., and W. Korotky, 1991: The SHARP workstation v1.50 users guide. National Weather Service, 30 pp. [Available from NWS Eastern Region Headquarters, 630 Johnson Ave., Bohemia, NY 11716.]

Houston, A. L., R. L. Thompson, and R. Edwards, 2008: The optimal bulk wind differential depth and the utility of the upper-tropospheric storm-relative flow for forecasting supercells. Wea. Forecasting, 23, 825-837, https://doi.org/10.1175/ 2008WAF2007007.1.
Johnson, A. W., and K. E. Sugden, 2014: Evaluation of soundingderived thermodynamic and wind-related parameters associated with large hail events. Electron. J. Severe Storms Meteor., 9 (5), http://www.ejssm.org/ojs/index.php/ejssm/article/ viewArticle/137.

Kahraman, A., and P. Markowski, 2014: Tornado climatology of Turkey. Mon. Wea. Rev., 142, 2345-2352, https://doi.org/ 10.1175/MWR-D-13-00364.1.

- S. Tilev-Tanriover, M. Kadioglu, D. Schultz, and P. Markowski, 2016: Severe hail climatology of Turkey. Mon. Wea. Rev., 144, 337-346, https://doi.org/10.1175/MWR-D-15-0337.1.

Kaltenböck, R., G. Diendorfer, and N. Dotzek, 2009: Evaluation of thunderstorm indices from ECMWF analyses, lightning data and severe storm reports. Atmos. Res., 93, 381-396, https:// doi.org/10.1016/j.atmosres.2008.11.005.

Lombardo, K. A., and B. A. Colle, 2011: Convective storm structures and ambient conditions associated with severe weather over the northeast United States. Wea. Forecasting, 26, 940 956, https://doi.org/10.1175/WAF-D-11-00002.1.

Markowski, P., and Y. Richardson, 2010: Mesoscale Meteorology in Midlatitudes. John Wiley and Sons, $430 \mathrm{pp}$.

Merino, A., E. García-Ortega, L. López, J. L. Sánchez, and A. M. Guerrero-Higueras, 2013: Synoptic environment, mesoscale configurations and forecast parameters for hailstorms in southwestern Europe. Atmos. Res., 122, 183-198, https:// doi.org/10.1016/j.atmosres.2012.10.021.

NCAR, 2014: The NCAR Command Language (version 6.2.0). UCAR/NCAR/CISL/VETS, http://dx.doi.org/10.5065/ D6WD3XH5.

Púčik, T., P. Groenemeijer, D. Ryva, and M. Kolar, 2015: Proximity soundings of severe and nonsevere thunderstorms in central Europe. Mon. Wea. Rev., 143, 4805-4821, https:// doi.org/10.1175/MWR-D-15-0104.1.

Rasmussen, E. N., and D. O. Blanchard, 1998: A baseline climatology of sounding-derived supercell and tornado forecast parameters. Wea. Forecasting, 13, 1148-1164, https:// doi.org/10.1175/1520-0434(1998)013<1148:ABCOSD>2.0.CO;2.

Renko, T., J. Kuzmic, V. Soljan, and N. S. Mahovic, 2016: Waterspouts in the eastern Adriatic from 2001 to 2013. Nat. Hazards, 82, 441-470, https://doi.org/10.1007/s11069-016-2192-5.

Shaltout, M., and A. Omstedt, 2014: Recent sea surface temperature trends and future scenarios for the Mediterranean Sea. Oceanologia, 56, 411-443, https://doi.org/10.5697/ oc.56-3.411.

Taszarek, M., and L. Kolendowicz, 2013: Sounding-derived parameters associated with tornado occurrence in Poland and Universal Tornadic Index. Atmos. Res., 134, 186-197, https:// doi.org/10.1016/j.atmosres.2013.07.016.

Thompson, R. L., R. Edwards, and J. A. Hart, 2002: Evaluation and interpretation of the supercell composite and significant tornado parameters at the Storm Prediction Center. Preprints, 21st Conf. on Severe Local Storms/19th Conf. on Weather Analysis and Forecasting/15th Conf. on Numerical Weather Prediction, San Antonio, TX, Amer. Meteor. Soc., J11-J14, https://ams.confex.com/ams/ pdfpapers/46942.pdf.

,,--- K. L. Elmore, and P. Markowski, 2003: Close proximity soundings within supercell environments obtained from the Rapid Update Cycle. Wea. Forecasting, $\mathbf{1 8}$ 1243-1261, https://doi.org/10.1175/1520-0434(2003)018<1243: CPSWSE $>2.0 . \mathrm{CO} ; 2$.

,-- , and C. M. Mead, 2004: An update to the supercell composite and significant tornado parameters. Preprints, 22nd 
Conf. on Severe Local Storms, Hyannis, MA, Amer. Meteor. Soc., P8.1, https://ams.confex.com/ams/pdfpapers/82100.pdf.

Tilev-Tanriover, S., A. Kahraman, M. Kadioglu, and D. M. Schultz, 2015: Lightning fatalities and injuries in Turkey. Nat. Hazards Earth Syst. Sci., 15, 1881-1888, https://doi.org/10.5194/nhess15-1881-2015.

Tuovinen, J., J. Rauhala, and D. M. Schultz, 2015: Significant-hailproducing storms in Finland: Convective-storm environment and mode. Wea. Forecasting, 30, 1064-1076, https://doi.org/ 10.1175/WAF-D-14-00159.1.

Westermayer, A., T. Púčik, P. Groenemeijer, and L. Tijssen, 2016: Comparison of sounding observations and reanalysis of thunderstorm environments. Eighth European Conf. on Severe Storms, Wiener Neustadt, Austria, European Severe Storms Laboratory, http://meetingorganizer.copernicus.org/ECSS2015/ ECSS2015-136-1.pdf. 